\section{Estudos de Comunidade e ciências sociais no Brasil}

Nemuel da Silva Oliveira ${ }^{1}$ e Marcos Chor Maio ${ }^{2}$

Resumo: O objetivo deste artigo é fazer um balanço da literatura sobre os Estudos de Comunidade (EC) no Brasil, destacando o contexto intelectual em que foram produzidos e os debates que suscitaram, especialmente entre as décadas de 1940 e 1960 . Método de pesquisa em comunidades, oriundo da Antropologia, em investigações sobre o processo de mudança social, os EC estiveram em voga nos Estados Unidos entre os anos 1920 e 1950, tendo papel fundamental na institucionalização das Ciências Sociais no Brasil. Destacamos três aspectos na produção desses estudos no país, iniciando com uma abordagem conceitual: definições, origem e sua relação com temáticas marcantes nos anos 1950. Em seguida, privilegiamos os aspectos relacionados ao papel dos EC na história das Ciências Sociais no Brasil, com destaque para o processo de institucionalização das Ciências Sociais. Por fim, revisitamos os debates que tais estudos geraram entre os cientistas sociais quanto ao padrão de trabalho sociológico a ser desenvolvido naquele momento. Palavras-chave: Estudos de Comunidade, História das Ciências Sociais, Mudança Social, Institucionalização das Ciências Sociais, Desenvolvimento.

\section{Introdução}

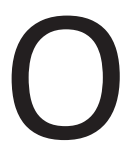

objetivo deste artigo é examinar os Estudos de Comunidade (EC) no Brasil, a partir do contexto intelectual em que foram produzidos, especialmente entre as décadas de 1940 e 1960. Recurso investigativo de comunidades em processo de mudança social, deslocando métodos de pesquisa afins à Antropologia, centrada inicialmente em sociedades "primitivas", para pesquisas em sociedades complexas, os Estudos de Comunidade estiveram em voga nos Estados Unidos desde a década de 1920, tendo papel fundamental na institucionalização das ciências sociais no Brasil. Destacamos três aspectos na produção desses estudos no país, iniciando com uma abordagem conceitual: definições, origem e sua relação com temáticas marcantes nos anos 1950, especialmente a mudança social. Em seguida, privilegiamos os aspectos relacionados ao papel dos EC na história das ciências sociais no Brasil, com destaque para o processo de institucionalização das ciências sociais. Por fim, revisitamos os debates que tais estudos geraram entre os cientistas sociais quanto ao padrão de trabalho sociológico a ser desenvolvido naquele momento.

Ao abordarmos a produção de EC no Brasil, observamos que, nas controvérsias
Recebido: 20/12/2010 Aprovado: $25 / 08 / 2011$

1. Doutorando do Programa de PósGraduação em História das Ciências e da Saúde da Casa de Oswaldo Cruz/ Fiocruz.

E-mail:

nemuel@gmail.com

2. Professor do Programa de Pósgraduação em História das Ciências e da Saúde da Casa de Oswaldo Cruz/ Fiocruz.

E-mail: maio@coc.fiocruz. br 
3. Acerca da visão que considera homogêneos os ensaios de interpretação do Brasil, $c f$. Botelho, 2010. em torno desses estudos, entre os anos 1940 e 1960, a visão crítica de alguns cientistas sociais prevaleceu sobre as considerações favoráveis que também lhe foram feitas. Não obstante, a força das críticas, a realização de EC permitiu o avanço do processo de institucionalização das ciências sociais no Brasil, com o treinamento de uma geração de pesquisadores mediante investigação de campo. Também por meio desses estudos, as ciências sociais revelaram importantes questões econômicas, políticas e sociais do contexto histórico do período, visto que estiveram voltadas para comunidades rurais em franco processo de mudança social, numa conjuntura marcada pela transformação de um país essencialmente rural e agrário em país urbano e industrial. O interesse em investigar os EC deve-se ao objetivo de compreender as relações entre sociedade e produção intelectual no contexto da era do desenvolvimento.

Os Estudos de Comunidade configuram modalidade de pesquisa em que a vida social de uma determinada comunidade, social e espacialmente localizada, é objeto de investigação minuciosa e detalhada. Trata-se de um "método de observação e exploração, comparação e verificação" cujo "propósito é, antes, o de usar a comunidade como um contexto para a exploração, a descoberta ou a verificação de interconexões entre fatos e processos sociais e psicológicos" (ARENSBERG \& KIMBALL, 1973, p. 171). Sendo a comunidade o pano de fundo em que se desenrolam os processos sociais sob investigação, os Estudos de Comunidade possuem caráter descritivo e abrangente, em que a necessidade de coleta de diversos dados para a compreensão da configuração da estrutura social como um todo é um princípio metodológico. O modelo de realização de Estudos de Comunidade que se estabeleceu no Brasil, especialmente durante a década de 1950, tem matriz norte-americana, em que os trabalhos de cientistas sociais como Robert Redfield e Robert E. Park são referências fundamentais (VILA NOVA, 1996, p. 69).

Os EC surgem no Brasil por meio da contratação de pesquisadores estrangeiros por instituições de ensino superior que haviam surgido na década de 1930 com destaque para a Escola Livre de Sociologia e Política de São Paulo, criada em 1933 (MICELI, 1989). Eles foram responsáveis pelo treinamento de pesquisadores nacionais, estiveram envolvidos em diversos desses estudos e tiveram grande influência na conformação de certa visão de trabalho do cientista social, que associava pesquisa de campo à intervenção na sociedade. A relação dos EC com o processo de institucionalização universitária das ciências sociais no Brasil reflete, também, a conjuntura em que tais ciências procuravam afirmar a sua cientificidade, contrapondo-se e buscando superar uma produção considerada de caráter ensaístico ${ }^{3}$ (CORRÊA, 1987). A partir da década de 1930, a reflexão social produzida por pensadores como Euclides da Cunha e Oliveira Vianna passou a ser objeto de questionamento. Para alguns cientistas sociais do período, 
deveria se consolidar uma nova perspectiva na produção das Ciências Sociais, fundamentada em objetividade e neutralidade.

A realização de EC no Brasil suscitou debates entre cientistas sociais, especialmente em relação às suas características teórico-metodológicas. Alguns dos que se manifestaram a favor da realização desses estudos chamaram a atenção para sua dimensão empírica e objetiva, considerada indicadora do caráter científico de que se pretendia dotar a produção de conhecimento no âmbito das ciências sociais. As manifestações contrárias aos EC destacaram, não raro, a invalidade e o alcance limitado dessas pesquisas para a compreensão das transformações sociais, políticas e econômicas no país naquele período. O debate em torno dos EC, na década de 1950, indica que havia a necessidade de investigar comunidades rurais que ainda mantinham algum grau de preservação da cultura tradicional, em franco processo de desaparecimento em meio ao desenvolvimento do país. A necessidade partia do entendimento de que era preciso intervir racionalmente nesse processo.

O conhecimento produzido por meio dos EC foi, ao longo dos anos 1950, cada vez mais entendido como necessário ao desenvolvimento de programas voltados para a transformação de determinadas regiões do país, com foco em suas realidades sociais, econômicas, sanitárias e educacionais. Foi também considerado útil para a formação e treinamento de profissionais nas técnicas de investigação das ciências sociais. Décadas mais tarde, com o declínio da realização de EC no Brasil $^{4}$, estes deixaram de figurar no debate acadêmico (CAVALCANTI, 1999, p. 186). Revisitamos, assim, a produção dos EC no Brasil, questionando o espaço a que foram relegados nesse debate, de forma a evidenciar seu papel na construção dos padrões de trabalho e produção intelectual das ciências sociais no país.

\section{Abordagem Conceitual e Caracterização dos Estudos de Comunidade no Brasil}

Desde os anos 1920, nos Estados Unidos (EUA), os Estudos de Comunidade configuravam um método investigativo de comunidades em processo de mudança social. Os pesquisadores Robert Lynd e Helen Lynd publicaram, em 1929, o estudo Middletown - a study in contemporary american culture, considerada pesquisa pioneira entre os estudos de comunidade americanos no século $X^{5}$. Os autores investigaram uma "típica" pequena cidade americana - na medida em que ela teria características comuns a um vasto grupo de outras pequenas comunidades -, com o objetivo de estudar, sincronicamente, tendências de comportamento que constituíam a vida comunitária (LYND, R. \& LYND, H., 1957[1929], p. 3). Mas, como surgiram e em que consistem os EC?
4. Na década de 1950, foram publicados dezoito EC; na década de 1960, quatro estudos; e apenas dois EC foram publicados na década de 1970, sendo os dois últimos publicados no Brasil (OLIVEIRA, 2010).

5. Jennifer J. Wallach, em nova introdução a Deep South: a social anthropological study of caste and class (2009 [1941], p. xiv), considera The Philadelphia $\mathrm{Ne}$ gro: a social study (1899), de W. E. B. Du Bois o trabalho pioneiro entre os Estudos de Comunidade americanos. 
Clifford Wilcox (2004), em seu trabalho sobre Robert Redfield, situa o surgimento dessa modalidade de investigação no processo de desenvolvimento da Antropologia norte-americana e, mais especificamente, do campo da Antropologia Social, no contexto da crescente profissionalização e especialização dentro das universidades americanas na virada para o século XX. Nesse período, destacavam-se o antropólogo Franz Boas, criador do primeiro programa de ensino de Antropologia nos Estados Unidos (Clark University) e professor de Antropologia da Columbia University (1899), e suas críticas às ideias evolucionistas e à perspectiva etnocêntrica que então predominavam entre os antropólogos. A abordagem preconizada por Boas para os estudos antropológicos estava centrada em investigações de campo de caráter empírico e histórico, que se tornou procedimento modelo de pesquisas até os anos 1920.

Robert Redfield, da University of Chicago, pertence à geração de antropólogos que, ao final dos anos 1920, começou a criticar a abordagem boasiana. Para Redfield, os procedimentos de pesquisa que esta envolvia tendiam a ignorar os aspectos ligados às mudanças que rompiam o tradicional modo de vida das tribos e grupos investigados, a fim de compor uma espécie de "fotografia etnográfica". Em contrapartida, Redfield afirmava que as mudanças deveriam constituir o cerne das investigações antropológicas. Afinal, durante a primeira metade do século XX, a velocidade e dimensão das transformações socioeconômicas nos EUA, efeitos principalmente da urbanização e da industrialização, provocando o acelerado crescimento populacional e problemas quanto aos serviços básicos da vida urbana, por exemplo, fizeram da ideia de mudança uma das principais características da vida moderna (ibidem, p. 2-3; LYND, R. \& LYND, H., 1957[1929] p. 5).

Foi nesse contexto de transformações que diversos antropólogos se voltaram para questões ligadas à mudança e à dinâmica social, tais como Bronislaw Malinowski, A. R. Radcliffe-Brown, Melville Herskovits, Ralph Linton, Robert Park, entre outros. Consoante Wilcox (op. cit., p. 4), o interesse desses pesquisadores resultou na emergência da chamada Antropologia Social, caracterizada pelo esforço de unir a abordagem científica generalizante da Sociologia, em que a temática da mudança se destacava, com a abordagem mais descritiva da Antropologia. As investigações se voltaram, então, para o estudo do processo de mudança social mediante a análise de áreas urbanas específicas, como comunidades de imigrantes, deslocando-se posteriormente para pequenas vilas no entorno dos centros urbanos, que se estavam transformando em decorrência do processo de industrialização.

Esses estudos de Antropologia Social em comunidades em processo de mudança se traduziram no que, posteriormente, Arensberg e Kimbal (1973) definiram como 
O método em que um problema (ou problemas) relativo à natureza, interconexões ou dinâmica do comportamento e atitudes é explorado o fundo ou no contexto de outros comportamentos e atitudes dos indivíduos que integram a vida de uma comunidade em particular. É um método naturalístico, comparativo. Visa ao estudo do comportamento e de atitudes como objeto in vivo, através da observação, mais que in vitro, através do isolamento e abstração, ou de um modelo, através da experimentação. (...) O estudo de comunidade é, então, um método de observação e exploração, comparação e verificação. Não é o estudo de uma comunidade, de comunidades ou da Comunidade. (...) Seu propósito é antes o de usar a comunidade como um contexto para a exploração, a descoberta ou a verificação de interconexões entre fatos e processos sociais e psicológicos. [grifos dos autores] (ARENSBERG \& KIMBALL, 1973, p. 169-171)

Consoante a definição dos autores, ao estudar os "fatos e processos sociais" que são obs ervados na dinâmica da vida comunitária, o pesquisador deve tratá-los enquanto dados a serem comparados com outra situação correlata, seja por aproximação ou por diferenciação. A comunidade emerge como contexto a partir do qual os dados não são apenas coletados, mas também analisados. Tal pode ser observado, por exemplo, no trabalho de Robert e Helen Lynd, Middletown (1957[1929]), ao levantar dados que permitiram analisar as tendências de mudança de comportamento processadas na comunidade num período de trinta e cinco anos. Os autores o fizeram mediante a comparação entre as características comportamentais de uma geração passada e da geração contemporânea à realização da pesquisa.

No caso brasileiro, os estudos centrados em análises comparativas de comunidades, a exemplo de O Homem no Vale do São Francisco, de Donald Pierson (1972), as mesmas foram selecionadas tendo em vista a possibilidade do estabelecimento de uma comparação entre tradição e mudança: uma delas deveria apresentar características tradicionais, no sentido de que a configuração social refletisse a permanência de valores, comportamentos e meios de vida cuja origem estivesse no passado, enquanto a outra, por oposição, características que refletissem maior proximidade dos valores, comportamentos e meios de vida mais modernos, mais afins aos centros urbanos.

Essa dimensão comparativa é uma importante marca da influência de Robert Redfield e da Escola de Chicago, que estão na matriz dos EC produzidos no Brasil (VILA NOVA, 1996, p. 69). Os trabalhos de Redfield no México, cuja metodologia fez parte dos cursos por ele ministrados na University of Chicago (WILCOX, 2004, p. 5) influenciaram cientistas sociais como Donald Pierson, que realizou e orientou diversos EC no Brasil. 
Os EC tiveram um leque variado de temas abordados. Alguns estudos realizados no âmbito do Projeto UNESCO de relações raciais, por exemplo, versaram sobre a situação racial brasileira, tendo em vista as mudanças decorrentes do processo de industrialização, que seria analisada pela investigação de áreas metropolitanas brasileiras (MAIO, 1999). No caso do Projeto Columbia University/Estado da Bahia, desenvolvido nos anos 1950, buscou-se subsidiar políticas de modernização do interior do estado mediante a investigação de três comunidades rurais próximas a Salvador (idem, 2009). Nessas pesquisas, as diferenças encontradas entre as comunidades evidenciavam o caráter das transformações socioculturais - mudanças nos hábitos alimentares, nos sistemas de comércio e divisão do trabalho, por exemplo - que os cientistas buscavam conhecer e interpretar.

Oracy Nogueira (1955a, p. 95) considerou os EC um método eficaz para a análise dos fenômenos ligados à transição de uma estrutura social tradicional para outra mais moderna. Salientando a importância dos EC, Nogueira incorporou o papel que se pretendia outorgar aos mesmos na produção das Ciências Sociais acerca da sociedade brasileira, ao afirmar que,

(...) do ponto de vista teórico, espera-se que os estudos de comunidade, à medida que se multipliquem, forneçam um complemento e, em certo sentido, um corretivo aos estudos de caráter analítico, por proverem uma visão de conjunto, funcional, da vida social, através da consideração e interpretação de dados sincrônicos e diacrônicos referentes ao mesmo locus geográfico (...). Em outras palavras, os estudos de comunidade permitem um exame mais adequado das manifestações subjetivas e interindividuais da vida social (ibidem, p. 98).

Para Nogueira, o caráter descritivo dos EC é um dos aspectos que contribuem para o embasamento das análises sociais que começaram a ser feitas no Brasil a partir da década de 1940 - o que faltava, a seu ver, em trabalhos publicados nos períodos anteriores. O investimento na produção desses estudos era essencial para alcançar uma visão ampliada sobre a sociedade brasileira. Nogueira propunha, fazendo uma crítica contundente ao ensaísmo, que essas interpretações mais gerais deveriam estar calcadas na pesquisa empírica, no levantamento de "dados" da vida social.

Arthur Ramos (1948, p. 224), analisando a produção da Antropologia no Brasil, também aponta os estudos monográficos, cujos principais trabalhos giravam em torno dos EC, como etapa importante para a construção de interpretações sobre a sociedade brasileira. Ele salientava a necessidade de "compreensão do ethos de determinada cultura parcial, o registro dos contatos e das mudanças e a apreensão da personalidade cultural", aspectos que poderiam ser apreendidos por meios dos EC. 
Uma característica dos EC é a ênfase dada a uma descrição, o mais abrangente possível, da vida social das comunidades, atrelada a elementos que recompusessem o seu desenvolvimento histórico. Com base em escritos de viajantes do século XIX, como Auguste de Saint-Hilaire e historiadores como Capistrano de Abreu, documentos públicos e eclesiásticos ou mesmo informações orais (PIERSON, 1972, I, p. 223-224), buscou-se, em alguns EC, estabelecer uma comparação entre a situação passada e a presente de uma determinada comunidade, a fim de identificar os elementos que expusessem o caráter e a dimensão do seu processo de mudança cultural.

Florestan Fernandes (1958, p. 220) se refere a tal característica como o "fascínio exercido pelo padrão de análise histórico-sociográfica". Primeiramente, Fernandes vincula esse fascínio à influência de autores como Tavares Bastos e Euclides da Cunha, representantes do que se convencionou chamar ensaios de interpretação do Brasil, e a partir dos quais muitos cientistas sociais ainda concebiam a explicação sociológica enquanto explicação histórica. Em seguida, afirma que essa era uma dimensão esperada na produção das ciências sociais pela intelectualidade daquele período. Acrescenta que as próprias características da sociedade brasileira alimentavam tal perspectiva, uma vez que fatores como os ciclos econômicos, por exemplo, acarretavam transformações socioculturais "facilmente percebidos através da análise histórico-sociológica" (ibidem) marcando a ascensão ou decadência de grupos sociais.

A análise de Fernandes ajuda a entender a dimensão histórica dentro de EC, como o de Lucila Hermann sobre Guaratinguetá, Evolução da Estrutura Social de Guaratinguetá num Período de Trezentos Anos (1948). A autora se propõe a "analisar o sentido da evolução histórica" da comunidade e, a partir da reconstrução de seus ciclos econômicos, "indagar quais as forças que agiram na formação sociológica de Guaratinguetá" (HERMANN, 1948, p. 307, 309). A pesquisa revelou três padrões culturais diferentes observados entre os quatro ciclos econômicos pelos quais passou - cultura de folk no ciclo da economia de subsistência, início das alterações nos dois ciclos posteriores (de abertura ao comércio externo à comunidade) e, por fim, predominância das características urbanas sobre a cultura local, com o surgimento de empresas voltadas para o mundo capitalista. Compreender-se-ia, assim, nessa perspectiva, a dinâmica da mudança social que se estabelecera na comunidade.

A dimensão histórica está também presente na pesquisa de Oracy Nogueira sobre relações raciais em Itapetininga (1955b), realizada sob os auspícios da UNESCO. Utilizando dados históricos, estatísticos, etnografia e observação direta (CAVALCANTI, 1999, p. 187), Nogueira abordou aspectos da estrutura social da comunidade que lhe permitiram estabelecer uma crítica à ideologia tradicional sobre as relações raciais no Brasil, em que prevalecia a visão de conciliação 
6. Nesse sentido, os povos indígenas foram os principais objetos de estudo da Antropologia no Brasil. Cf. Ramos, 1948, p. 213-217. em detrimento dos conflitos existentes entre brancos e negros. Mediante a temática das relações raciais, Nogueira investigou o processo de mudança, na medida em que influenciava os mecanismos de ascensão social e, portanto, a própria estrutura da sociedade (MAIO, 2008, p. 40-44).

Os EC configuram, ainda, um recurso de pesquisa dificilmente enquadrado como pertencente somente à Antropologia ou à Sociologia. Estão, na verdade, situados numa zona interseccional, cuja análise depende do reconhecimento das contribuições de ambas as disciplinas. Importantes características dos EC foram herdadas da Antropologia, como métodos de investigação calcados na observação direta dos fenômenos pesquisados. Suas análises, desde que se constituiu enquanto disciplina autônoma no século XIX, recaíram largamente sobre os povos considerados "primitivos"6 . Não obstante, os mais diversos aspectos da vida humana seriam alvo do estudo dos antropólogos. Dos sistemas econômicos, às crenças e religiões, vigia a perspectiva de que tudo o que se relacionasse ao homem seria contemplado pela Antropologia (VILLAS BÔAS, 2007, p. 97-98).

Da Sociologia, os EC incorporaram principalmente os temas abordados, seja no que concerne às mudanças sociais, industrialização e desenvolvimento, ou no que respeita ao meio rural - condições e relações de trabalho, relações políticas, movimentos e conflitos religiosos e tradições populares (ibidem, p. 113-115). A abordagem da mudança na Sociologia está ligada à compreensão da estrutura da sociedade, de como ela se altera, o que nos remete ainda a duas outras questões também presentes nos EC: as resistências que a sociedade oferecia a tais mudanças e a ideia do lapso existente entre os dois pólos de ajustamento social, onde o processo de mudança era o momento intermediário, conhecido pela tese da cultural lag (demora cultural) (OGBURN, 1964).

A resistência à mudança é um dos aspectos que configura o processo de transformação da estrutura social. Tem também implicações no que concerne à chamada demora cultural, no sentido de que acentua o descompasso entre um momento de "estabilidade" ou ajustamento social e outro posterior à mudança ocorrida. Segundo William Ogburn,

(...) uma demora cultural ocorre quando uma de duas partes da cultura que são correlatas muda antes ou em maior grau que a outra parte, causando deste modo menor ajuste entre as duas partes, do que existia anteriormente [tradução livre]. (OGBURN, 1964, p. 86)

Nesse sentido, especialmente nos EC, centrados na comparação de comunidades rurais, os pesquisadores investigaram as condições de vida das comunidades no passado, coletaram os dados no seu tempo presente e assim pretenderam conhecer o processo de mudança que estava não apenas no 
intervalo entre momentos de maior ajustamento social, mas que para eles estava então acontecendo. A captação do desenrolar do processo é o que conferiria aos seus estudos a possibilidade de "surpreender" a mudança, prever as resistências e tornar efetivas as transformações pleiteadas pelo poder público rumo ao desenvolvimento.

Os cientistas sociais se preocupavam em antecipar os efeitos negativos das mudanças socioculturais, como a possibilidade de desestruturação da sociedade em decorrência de transformações demasiadamente profundas ou abruptas. Alguns projetos, como o executado na comunidade de Chonin, em 19517 , já haviam se deparado com esse tipo de situação, o que reforça a ideia de articulação entre cientistas sociais e projetos de mudança.

A temática da mudança catalisou a participação de cientistas sociais nesses projetos voltados para o desenvolvimento, fornecendo conhecimentos sobre a dimensão social e econômica do país (VILLAS BÔAS, 2006, p. 70). Esse conhecimento social seria capaz de informar as variações e aspectos da resistência oferecida pelas populações, indicando a dimensão e o ritmo em que as mudanças deveriam se processar, a fim de que significassem realmente o desenvolvimento desejado (MAIO \& LIMA, 2009, p. 551-552).

Os EC podem ser identificados como uma interface entre Antropologia e Sociologia, pois embora tivessem marcas metodológicas afins à Antropologia, a perspectiva dos estudos era fortemente sociológica, na medida em que, ao conhecer as comunidades, buscava-se identificar a mudança social, tema caro à Sociologia. A aplicação do método da "antropologia social da comunidade" expressão utilizada por Arthur Ramos, em 1948, para se referir aos EC (RAMOS, op. cit., p. 224), ilustra bem o caráter interseccional desses estudos em relação às duas disciplinas.

Vale assinalar que as tensões fronteiriças entre Antropologia e Sociologia, embora pareçam diluídas nos EC, constituíram questão importante a partir da institucionalização universitária das ciências sociais. Sem entrar numa discussão pormenorizada sobre a questão, é importante observar, todavia, que a produção de EC no país acontece num período também marcado pelos embates identitários entre as disciplinas. Assim, tais estudos ora foram apontados como elementos de proximidade entre ambas, ora - com predominância das críticas - foram tomados como marca de distinção. Dois aspectos dessa relação entre as disciplinas das ciências sociais, apontados por Bila Sorj (1999, p. 224), são fundamentais para compreender esta discussão, um aspecto empírico e outro analítico.

Sobre o primeiro aspecto, de caráter empírico e objetivo, a autora afirma que as possíveis diferenças entre as disciplinas não são concretas o bastante
7. O antropólogo norte-americano Kalervo Oberg realizou uma pesquisa na comunidade de Chonin (MG) para avaliar a execução de um programa de desenvolvimento rural executado naquela comunidade, em 1951, sob a ótica do impacto social causado pelas intervenções nos setores saúde, educação e agricultura. O projeto fracassou, segundo indicou Oberg, por não ter considerado devidamente as questões socioculturais que compunham a estrutura organizacional da comunidade (OBERG, 1961, p. 43-52). 
para reivindicações de campos e objetos próprios de pesquisa, reforçando a ideia de proximidade (ibidem). Antônio Cândido (1958), ao tratar da Sociologia em São Paulo, e Cavalcanti (1999), da relação entre Donald Pierson e Oracy Nogueira, nos anos 1940, chamam a atenção para a compenetração entre Antropologia e Sociologia, fosse pela abordagem e temáticas investigadas, fosse pela localização institucional dessa compenetração - a Escola de Sociologia e Política de São Paulo. De fato, muitos dos EC foram produzidos por professores e alunos da ELSP, onde a formação no curso de Sociologia, pelas características profissionais do corpo docente, tinha um viés marcadamente antropológico, especialmente em razão da natureza empírica das investigações.

O segundo aspecto da relação fronteiriça entre as disciplinas, apontado por Sorj, tem caráter analítico e sociológico, em que a autora considera a separação como resultado de sua construção social e cognitiva, gerando tradições intelectuais e institucionais distintas. Nesse aspecto, em que pesem a variedade e imprecisão das justificativas e a presença de diferentes perspectivas dentro de cada uma delas, não deve ser desprezado o valor organizacional que a divisão confere ao campo das ciências sociais (SORJ, op. cit., p. 224).

Sobre esse ponto, Luiz A. Costa Pinto (1970[1963], p. 76) é bastante enfático ao criticar os EC e seu "approach multidisciplinar", para reafirmar a eminência da Sociologia para a compreensão da sociedade brasileira em relação a outras disciplinas das ciências sociais. Para o autor, a Sociologia seria a única disciplina que reuniria formas de abordagem e refinamento teórico para dar inteligibilidade às questões sociais brasileiras no contexto do desenvolvimento. Ao procurar definir as fronteiras da Sociologia em contraste com a Antropologia, Costa Pinto reforça, pois, as diferenças entre elas. Sob outra perspectiva, baseada na organização temática da produção das ciências sociais no Brasil, o trabalho de Villas Bôas (2007) mostra que havia diferenças entre Antropologia e Sociologia, evidenciadas pelas trajetórias distintas que cada uma das disciplinas logrou em relação a suas publicações.

Mediante as argumentações que aproximam ou distanciam as disciplinas, vemos que os EC, especialmente no contexto de sua maior produção, constituíram elemento catalisador desse debate interdisciplinar, assumindo papel importante no estabelecimento de tradições institucionais e de pensamento sociológico e antropológico no Brasil.

\section{Os Estudos de Comunidade na História das Ciências Sociais no Brasil}

Os Estudos de Comunidade produzidos no Brasil, não obstante as singularidades de cada pesquisa, estão relacionados ao período de institucionalização das 
ciências sociais no país, especialmente a partir da criação da Escola de Sociologia e Política de São Paulo nos anos 1930, que inaugurou novos tempos na produção das ciências sociais brasileiras, compreendendo os anos de "gestação" dos EC brasileiros. A "novidade" dos tempos se deve ao fato de que os EC

(...) foram canalizados para a Sociologia no Brasil como parte de um movimento intelectual na década de 30 voltado à consolidação de uma consciência científica na compreensão da realidade nacional. Operando uma revisão crítica da tradição acadêmica que os precedia, os estudos de comunidade, por seu embasamento empírico, se figuraram então como a alternativa mais legítima para substituição dos modelos explicativos anteriores, contestados como conjecturais e paracientíficos. (GOLDWASSER, 1974, p. 74)

Os EC estão, pois, vinculados a certo momento de desenvolvimento das ciências sociais no país, tendo constituído um esforço de se contrapor e superar trabalhos considerados de caráter ensaístico, em que prevaleciam interpretações gerais sobre a sociedade brasileira (BOTELHO, 2010). Colocá-los "entre parênteses" foi a expressão utilizada por Mariza Corrêa (1987, p. 21) para ilustrar como as ciências sociais recém-institucionalizadas se posicionaram em relação aos chamados ensaios de interpretação do Brasil. O embasamento em dados concretos da realidade social referido por Goldwasser seria, então, o elemento que traria a produção científica sócio-antropológica brasileira ao cânon da produção "verdadeiramente" ${ }^{8}$ científica, por revesti-la de objetividade.

Corrêa (ibidem) destacou três momentos da produção das ciências sociais brasileiras: um primeiro "que poderíamos chamar de o momento das 'grandes sínteses', [compreendia] as avaliações globais da sociedade brasileira feitas pelos seus intelectuais (tendo como exemplos Oliveira Vianna, Sérgio Buarque de Holanda, Gilberto Freyre)"; um segundo, representado pelo seu processo de institucionalização com a criação dos centros acadêmicos nessa área; e um terceiro, "inaugurado com a reforma do ensino universitário no final da década de 60 - e cuja expressão são os cursos de pós-graduação".

No início da década de 1930, surgem importantes centros de formação profissional na área das ciências sociais em Pernambuco, Bahia, Minas Gerais, Rio de Janeiro e São Paulo. Neste estado, as principais referências são a Escola Livre de Sociologia e Política (ELSP), criada em 1933, e a Faculdade de Filosofia, Ciências e Letras (FFCL), da Universidade de São Paulo (USP), criada em 1934. Vale ressaltar que tais instituições representavam o esforço de profissionalização de cientistas sociais no país, muito embora, conforme destacaram Arthur Ramos (1948, p. 225) e Florestan Fernandes (1950, p. 442) anos depois, o desenvolvimento das ciências sociais permanecera incipiente, havendo uma desproporção
8. Entre aspas para marcar que essa era uma visão que deve ser entendida em seu contexto histórico e intelectual específico. 
9. A cidade de Chicago, nas primeiras décadas do século $X X$, oferecia a essas perspectivas sociológicas um profícuo campo de pesquisas sociais, em razão dos efeitos da urbanização e da industrialização, que provocaram um acelerado crescimento populacional e uma crise nos serviços básicos da vida urbana. Esses fatores puderam ser integrados à produção sociológica pelo fato de a disciplina ser naquela universidade, entendida como um instrumento de reforma social (OLIVEIRA, op. cit., $\mathrm{p}$. 72). entre o vasto "acervo dos bens da cultura material" (RAMOS, op. cit., p. 225) e o reduzido número de profissionais qualificados para seu estudo.

A produção de EC no Brasil esteve ligada ao processo de institucionalização das ciências sociais no Brasil, especialmente por meio das atividades desenvolvidas na ELSP. A Escola, cuja criação é um marco na história das ciências sociais no Brasil, promoveu muitos estudos voltados para populações interioranas. Sua relação com a produção das ciências sociais da Universidade de Chicago se estabeleceu por meio de professores estrangeiros contratados para compor seu corpo docente, como Emilio Willems, Herbert Baldus e, especialmente, Donald Pierson. Este pode ser considerado um dos principais representantes, no Brasil, das perspectivas de produção sociológica norte-americana que ficaram conhecidas como Escola de Chicago.

Segundo Lúcia Lippi Oliveira (1995), a Universidade de Chicago foi a primeira a institucionalizar a produção das ciências sociais, criando um departamento de Sociologia com cursos de pós-graduação, supervisão de pesquisas, publicação de periódicos, e com interesse específico na articulação do campo teórico com a observação empírica, uma vez que as condições socioeconômicas de Chicago impulsionavam as pesquisas ${ }^{9}$. Mediante o trabalho de Robert E. Park, que foi, inclusive, orientador de Pierson, consolidou-se uma perspectiva sociológica caracterizada pela observação direta, pelo uso de depoimentos e histórias de vida, atenta aos processos de mudança social (MASSI, 1989, p. 435), e que via na investigação dos fatos sociais uma possibilidade de intervenção.

Pierson trouxe consigo essa visão de como deveria ser e que finalidade teria o trabalho do sociólogo profissional. Haja visto as transformações econômicas e sociais pelas quais passava o Brasil, aliaram-se à sua visão as ideias da elite paulista, que fundou a ELSP, desejosa por um protagonismo na condução do país à modernidade. $O$ processo de institucionalização das ciências sociais no Brasil sugere, assim, uma articulação entre o desenvolvimento dessas ciências e o ideário de modernização do país, que se refletiu nos trabalhos produzidos nesse período. Como aponta André Botelho (2008, p. 274), "são as instituições que viabilizam, num plano, a reprodução da própria ideia de ciência como um valor distintivo da modernidade".

Nísia Trindade Lima (1999, p. 155-209), ao analisar diferentes versões da história das ciências sociais no Brasil, mediante os trabalhos de cientistas como Guerreiro Ramos, Roger Bastide, Mariza Peirano, Wanderley Guilherme dos Santos, entre outros, mostra a pluralidade de motivações que fundamentaram a produção sócio-antropológica pós-institucionalização universitária. Essa pluralidade fundamenta sua crítica à abordagem que acentua o marco institucional como principal referência para a adoção de padrões científicos por parte dessas 
ciências e para sua articulação com os problemas nacionais.

Segundo a autora, tal abordagem naturaliza o processo de institucionalização, desvalorizando importantes contribuições do período anterior para interpretações da sociedade brasileira. Por outro lado, cria uma estereotipia em torno das diferentes instituições de ensino e pesquisa que surgiram na década de 1930, o que dificulta a consideração mais profunda dos diversos referenciais políticos e também teórico-metodológicos de trabalho adotados por essas instituições. A crítica também se volta para a ênfase excessiva na dicotomia ciências sociais cariocas/ciências sociais paulistas, em detrimento de possíveis semelhanças (ibidem).

O referencial adotado pela ELSP foi a formação de um modelo de sociólogo profissional, voltado para pesquisas empíricas e apto a seguir carreiras administrativas. A finalidade técnica da Escola era mais acentuada que noutras instituições de ensino superior criadas nesse período, como a FFCL (LIMONGI, 1989; BOMENY, 2001). Limongi faz uma verdadeira "radiografia" das duas instituições, discorrendo sobre os profissionais que nelas trabalharam, suas matrizes acadêmicas e os desdobramentos de sua influência na produção antropológica e sociológica, os modelos de ensino e pesquisa que foram utilizados, com destaque para os modelos americano (na ELSP) e francês (na FFCL) ${ }^{10}$. Jackson (2007) aborda as tensões e disputas entre ELSP e FFCL/USP, especialmente quanto aos seus projetos institucionais e suas perspectivas de pesquisa e análise, articulando-as ao momento de afirmação da cientificidade das ciências sociais em plena conjuntura, marcada pelo desenvolvimento do país. Mediante os debates travados em torno dos ensaios de interpretação do Brasil, como Casa Grande e Senzala, de Gilberto Freyre, e dos estudos de comunidade, como Cunha, de Emilio Wille$\mathrm{ms}$, Jakson mostra que as diferenças entre as instituições apontavam questões mais amplas, como o embate entre ensaio e ciência, entre teoria e pesquisa empírica e entre sociologia do desenvolvimento e da cultura.

Observa-se então, a partir da criação das referidas instituições, uma mudança no processo de produção do conhecimento socioantropológico, no qual as investigações de campo, sob influência de pesquisadores estrangeiros como Donald Pierson, constituem um elemento importante nesse novo curso da história das ciências sociais no Brasil. Entretanto, uma importante característica distintiva das ciências institucionalizadas em relação ao ensaísmo reside justamente na consciência que os cientistas sociais desenvolveram acerca da sua própria produção intelectual e do seu papel na comunidade científica, como aponta André Botelho:
10. Sobre as influências norte-americanas e francesas dentro das instituições de ensino superior no Brasil, $c f$. Massi, op. cit.

(...) o ensaísmo não expressa a organização e a atuação de um grupo de indivíduos/autores com interesses coletivos comuns programáticos 
e deliberados, a despeito de seus conflitos e disputas internas. Aspectos que também afastam o ensaísmo das ciências sociais institucionalizadas, cujos atores se mostram, em geral, altamente conscientes de seus objetivos, regras de atuação e ethos enquanto cientistas sociais. (BOTELHO, 2010, p. 48)

O trabalho de pesquisadores como Donald Pierson contribuiu não somente para o conhecimento da sociedade brasileira, mas também para a afirmação da importância do papel dos cientistas sociais na formação de seu próprio ofício e do seu campo de conhecimento. Foi a dupla chave - a contratação de pesquisadores estrangeiros e a introdução da investigação de campo - que levou a Sociologia e Antropologia a alcançarem, aqui, o estatuto de disciplinas científicas, voltadas tanto para uma educação que preparasse profissionais para atuação nos setores econômicos, administrativos e políticos, como também para a criação de recursos a partir dos quais se pudessem solucionar os problemas sociais brasileiros.

\section{Os debates em torno dos Estudos de Comunidade}

Os debates em torno dos EC atestam que sua produção não se deu sem disputas, embate de ideias, defesas e críticas. Boa parte dessa discussão se deu no momento em que um número significativo desses estudos era realizado no país, especialmente durante as décadas de 1940 e 1950. Faz-se mister, então, levantar algumas questões dentro desse debate, começando pela indicação das suas contribuições à produção das ciências sociais.

Um dos primeiros aspectos acerca das contribuições dos EC à produção sócioantropológica, de acordo com Oracy Nogueira (1955a, p. 98), está relacionado ao momento na história das ciências sociais no Brasil, caracterizado pelo esforço intelectual de superação da produção sociológica anterior ao processo de institucionalização dessas ciências, considerada conjectural e não científica. Os EC seriam, também, segundo Nogueira, o método mais eficaz de investigação do processo de mudança social, uma vez que, por meio desses estudos, seria possível examinar de maneira mais adequada as relações interpessoais, as "manifestações subjetivas e interindividuais da vida social, revelando a tendência do grupo a perpetuar seus valores tradicionais ou a abandoná-los e substituí-los por outro sistema de valores" (ibidem). Dessa forma, pela observação factual da vida social, através da identificação das formas culturais a partir de situações concretas, seria possível realizar uma verificação direta das hipóteses formuladas no projeto de pesquisa, confirmando-as ou não, o que exigiria a formulação de novas hipóteses (CONSORTE, 1956, p. 67). 
Outro aspecto dos EC, nesse período, refere-se à contribuição que o conhecimento produzido sobre a realidade social das comunidades estudadas poderia oferecer aos projetos de mudança que, tanto o governo federal, quanto outras instituições (educacionais, sanitárias, etc.) estavam implantando no interior do país (WAGLEY \& AZEVEDO, 1951; CONSORTE, 1956; IANNI, 1961). Essa é uma importante chave de compreensão da relação entre a história das ciências sociais no Brasil e a conjuntura desenvolvimentista de meados do século $X X$.

Emilio Willems e Oracy Nogueira são autores que chamam a atenção para a dimensão auxiliar que os EC poderiam assumir no trabalho dos agentes de mudança social e cultural (médicos, engenheiros, educadores, sanitaristas, entre outros). O conhecimento socioantropológico produzido pelos EC apontava a necessidade de um maior contato - por parte destes técnicos - com as características socioculturais das populações-alvo dos projetos de desenvolvimento, independente do foco de cada um desses projetos.

A participação de diferentes profissionais era mais um indicativo de que deveria haver várias frentes de ação na solução dos problemas das comunidades do interior do país. Todavia, Willems (1943, p. 21) destaca que, se cada técnico atuasse em sua área de forma desarticulada às demais, dificilmente os projetos teriam êxito. O autor, já no início da década de 1940, percebia que cada especialidade técnica se ocupava de um problema particular e procurava resolvê-lo:

Para os médicos, o caboclo é um doente e um sub-alimentado; para o educador, todo "mal" reside no analfabetismo; o agrônomo verifica a inexistência de conhecimentos "racionais" de agricultura; os economistas dão pela falta de crédito, de mercados e meios de comunicação, os moralistas desejam erradicar certos "vícios", e assim por diante. (ibidem)

Dessa forma, sem uma visão de conjunto da vida social das comunidades, dada pela investigação de seus elementos socioculturais, a mudança cultural teria um efeito limitado ou pouco duradouro. Os estudos de cientistas sociais, então, ordenariam o processo de mudança, visto que apontavam para a necessidade de um planejamento prévio que levasse em consideração tais características, no intuito tanto de gerar, nos agentes de mudança, uma atitude mais compreensiva acerca das populações com que lidavam, quanto de aumentar a eficácia das transformações (NOGUEIRA, 1955a, p. 98).

Isso seria possível porque os EC informariam as condições que favoreciam ou não as mudanças projetadas, permitindo que, durante o planejamento, técnicas de informação e convencimento fossem utilizadas. Além disso, Nogueira também identificava nos EC uma maneira de mostrar à administração pública 
as reais necessidades das populações interioranas, corrigindo a tendência político-administrativa de concentrar esforços na solução dos problemas dos centros urbanos em detrimento da zona rural do país (ibidem, p. 99).

As considerações de Nogueira sobre os EC são sintomáticas do momento específico de desenvolvimento das ciências sociais no país, conforme ressaltamos anteriormente, quanto ao processo de institucionalização. Por isso mesmo, ajudam a compreender de que maneira tais estudos estão incluídos num movimento de defesa de certa visão do trabalho do cientista social, da cientificidade daquilo que produz e do seu papel social e político. A dimensão intervencionista e de reforma social que se consolidava na produção das ciências sociais nesse período, como também apontou Fernandes (1950, p. 443), reforçava a afirmação de ciências sociais então modernas, pautadas na profissionalização acadêmica e na experiência positiva de pesquisa, articulada à sua problematização teórica. Acentuava-se, assim, o propósito de interpretar cientificamente a sociedade brasileira e, sobretudo, de indicar soluções para seus problemas.

Os EC foram objeto, também, de críticas por diversos autores, especialmente em relação à metodologia e ao arcabouço teórico. De maneira geral, eles reconhecem que essas pesquisas trouxeram contribuições para a produção de conhecimento acerca da realidade social, como vimos anteriormente. No entanto, é recorrente entre os críticos a consideração de que os problemas relativos aos EC residem não apenas no método, ou em sua acurada aplicação, mas no alcance da análise que é feita por meio dele. Nesse sentido, Prado Júnior (1948) chama a atenção para a carência da exposição e exploração de um quadro teórico substancial que dessem conta do volume de informações levantadas pelo método de pesquisa utilizado nos EC e que tornassem possível a produção de uma verdadeira análise socioantropológica.

Primeiramente, é preciso ressaltar que sua avaliação é feita a partir do estudo sobre Cunha de Emilio Willems, publicado em 1947. Willems fez parte do corpo docente da ELSP (regeu as cátedras de Sociologia e Antropologia Social), da USP (cátedra de Antropologia), e é um dos fundadores da revista Sociologia. De acordo com Villas Bôas (2000, p. 172), a importância de Willems para as ciências sociais brasileiras reside especialmente "na perspectiva que imprimiu ao seu trabalho intelectual, voltado enfaticamente para o conhecimento da mudança cultural".

O estudo de Cunha é pioneiro no país nesse tipo de pesquisa. Willems tinha por objetivo investigar o caráter das transformações socioculturais pelas quais a comunidade de Cunha, que fica no interior paulista, estava passando, em razão especialmente do fim de seu isolamento, com a construção de uma estrada de rodagem, ligando-a a Guaratinguetá (WILLEMS, op. cit.). 
Nesse trabalho, Willems trata dos aspectos gerais da comunidade, da sua história, informações demográficas e da mobilidade espacial; da estrutura social, como a estratificação das classes sociais, as relações vicinais e familiares, e as associações religiosas, políticas e de outros tipos; também da cultura, discorrendo o autor sobre a organização econômica, alimentação, vestuário, habitação e mobiliário, indústrias domésticas, o universo mágico e religioso e as festas anuais. Willems apresenta, ainda, um resumo dos dados e suas conclusões na pesquisa, em que destaca que os fatores de estabilidade social estavam ligados à força da tradição, enquanto os de instabilidade, ligados às inovações que chegavam à comunidade com o rompimento do seu isolamento (ibidem, p. 168).

Gioconda Mussolini, aluna de Willems na ELSP, participou das pesquisas em Cunha e na ilha de Búzios ${ }^{11}$. Em resenha do estudo sobre Cunha, a antropóloga afirma:

Ao lado das tendências à transformação são analisadas outras que revelam "o grau de resistência que a comunidade opõe à mudança", os "inúmeros fatos específicos que caracterizam a persistência da tradição", "resistindo às tendências de individualização" [p. 90]. Em resumo, transição a partir da tradição, por impacto de novas forças, revelando "a capacidade que a comunidade local demonstra em acomodar seus antagonismos e conflitos internos" [p. 164]. (MUSSOLINI, 1949, p. 479)

No ano seguinte à publicação de Willems, Caio Prado Jr. (1948, p. 24) expôs sua preocupação tanto em avaliar a legitimidade do uso do método, como mensurar suas contribuições para as ciências sociais. Ele observa que o método, por carecer de elementos que articulem os dados, "num conjunto coerente e cientificamente sistematizado", compromete sobremaneira o resultado do trabalho. $\mathrm{O}$ problema não estaria apenas na maneira em que o método foi utilizado, mas na sua própria utilização para alcançar os fins propostos para a pesquisa. Segundo o autor, não é possível identificar "qualquer ideia diretriz" que oriente a pesquisa. Logo, os critérios levados em consideração para a escolha da comunidade a ser investigada, ou quaisquer outros usados em etapas posteriores, não estariam fundamentados em um quadro teórico apropriado para dar inteligibilidade à gama de informações coligidas e servir de base para uma análise de caráter científico.

Os dados coletados na pesquisa estariam, pois, devidamente identificados, expostos, compartimentados, mas o processo de mudança que eles deveriam informar permanecia inacessível, pois não haveria, entre os mesmos, uma conexão clara que fosse iluminada pela teoria. Segundo Consorte (1956, p. 68), nos EC, haveria apenas a descrição dos aspectos da cultura em que se percebe a mudança social e dos fatores que a impulsionaram e
11. A pesquisa realizada com Willems, em 1947, nessa localidade foi publicada em 1952: Buzios Island - a caiçara community in southern Brazil. Seattle, University of Washington Press. Sobre a trajetória intelectual de Mussolini, ver $\mathrm{CIACCHI}$ Andrea. "Gioconda Mussolini: uma travessia bibliográfica". Revista Antropologia, vol. 50, n. 1, 2007. 
não uma análise mais consistente da forma pela qual se procedeu tal mudança.

Na mesma direção, aponta Gioconda Mussolini (op. cit., p. 480), ao final de sua resenha sobre o livro de Willems:

(...) a obra sobre Cunha dá a impressão de uma fuga deliberada da teoria explícita. Ao trabalho sobre Cunha - excelente fonte de material e análises, ponto de referência para futuros estudos - falta, a nosso ver, uma certa interação entre as proposições gerais que lhe serviram de base e os fatos particulares que ilustra, numa redefinição daquelas proposições, que impedisse a impressão de reificação de conceitos.

É justamente a reificação de conceitos, nos EC, um dos pontos de crítica da socióloga Maria Sylvia F. Moreira (1963, p. 37-38). Para a autora, a forma de captação das relações comunitárias nesses estudos enfatiza, sobremaneira, os elementos de preservação da ordem social, apontando os aspectos mais estáveis da comunidade. Por isso mesmo, os EC careciam de um arcabouço teórico útil à apreensão dos fatores de mudança social. Ainda que os estudos revelassem o grau de desorganização social nas comunidades investigadas, os trabalhos não ultrapassariam a indicação de quais elementos sofreram maior ou menor impacto em relação a possíveis transformações, permanecendo inacessível o processo de mudança.

A ausência, nos EC, da interação entre os dados e as proposições teóricas que devem orientar uma pesquisa social - como registrou Mussolini, foi objeto da comunicação do sociólogo Levy Cruz, no Segundo Congresso Latino-americano de Sociologia, realizado no Rio de Janeiro, em 1953. Na ocasião, Cruz se contrapunha a essa visão e chamava a atenção para a existência de hipóteses ou "expectativas" teóricas informando a realização de EC, ainda que elas não estivessem explicitamente presentes nos relatórios de pesquisa. Ele argumentava, a partir de sua experiência na coordenação de uma pesquisa, no Vale do São Francisco, no início dos anos 1950, que a investigação contribuía para o conhecimento da sociedade mais pela obtenção de dados que permitiam formular análises, do que pela possibilidade de testar hipóteses previamente concebidas. Entretanto, reiterava a necessidade de apresentação, por parte dos pesquisadores, das hipóteses e resultados da investigação nos EC, a fim de "equacionar as implicações teóricas nos seus estudos” (CRUZ, 1953, p. 260-265).

O problema referente à dimensão da teoria nos EC também é colocado por Sérgio Buarque de Holanda (1979[1948], p. 132), apontando a tensão entre Antropologia e Sociologia: no conjunto de teorias que informava o estudo de comunidades primitivas - campo de atividades da Antropologia -, as questões da homogeneidade e estabilidade da organização social eram primordiais, as- 
sim como as ideias de autossuficiência e caráter unitário da comunidade. Com os EC, que se voltavam então para o estudo de comunidades não primitivas, esse conjunto de teorias teria se tornado inadequado à análise pretendida, uma vez que a realidade social investigada não apresentava tão estritamente a homogeneidade, estabilidade, autossuficiência ou unicidade observada nas comunidades primitivas. Com isso, a utilização rígida do método antropológico na investigação das comunidades interioranas, sem levar em conta a fluidez dos contatos da comunidade com situações sociais externas, poderia limitar o alcance analítico dos EC.

Se, por um lado, as críticas de Moreira (1963) e Holanda (1979[1948]), acima referidas, apontam limitações dos EC, mais contundentes são as críticas de L. A. Costa Pinto (1970[1963]) e, posteriormente, Klaas Wortmann (1972), que questionam a própria validade desses estudos enquanto pesquisa social.

As objeções de Costa Pinto e Wortmann recaem principalmente sobre o caráter culturalista dos EC. Ao estudar a sociedade civilizada como se fosse primitiva, segundo Costa Pinto (op. cit., p. 79; 85-86), os EC encarnam uma "distorção metodológica" que lhes confere características essencialmente descritivas, impossibilitando o desenvolvimento de uma problemática específica, pois o esquema conceitual dos antropólogos não permitia analisar os fenômenos sociais próprios de comunidades não primitivas e em processo de mudança. Crítica semeIhante o autor havia feito aos estudos sobre o negro no Brasil, mostrando que a tradição de estudos sobre as relações raciais, fundamentadas em trabalhos de etnografia e antropologia, numa abordagem voltada para o "exotismo cultural" de seu objeto, havia escapado às análises de caráter sociológico, que procura "analisar o problema dentro do quadro total em que as relações de raças concretamente se estabelecem" (idem, 1998[1953], p. 62).

Já, segundo Wortmann (op. cit., p. 132-135), o caráter culturalista dos EC os conduz a uma visão idealista da realidade social estudada, em que os estereótipos e modelos que informam a pesquisa substituem a própria realidade. Leva-os também à desconsideração das estruturas nacionais e suas manifestações locais, apesar de serem julgadas inteligíveis mediante a análise de suas múltiplas relações. Além disso, o culturalismo dos EC impossibilita generalizações - em função dos problemas de representatividade das comunidades -, deixando incompleto o trabalho científico e tornando os dados levantados na pesquisa improdutivos, pois, segundo o autor,

Não é simplesmente a partir dos dados da realidade empírica - limite dos estudos de comunidade - que se alcança a explicação dos sistemas sociais. Somente a partir de conceitos da realidade abstrata é possível entender sistemas como totalidades concretas. (ibidem, p. 134) 
12. Consorte (1996, p. 59), ao tratar das críticas de Octávio lanni aos EC (1961), também destaca o distanciamento temporal em que as críticas foram feitas, bem como o seu distanciamento intelectual em relação a tais estudos, visto que não produziu nenhum EC, nem participou de projetos afins. Suas críticas advinham da sua militância como sociólogo, das questões das ciências sociais de então, que informava sua atividade intelectual.

13. Comunicação feita naquele ano, na I Reunião Brasileira de Antropologia, no Rio de Janeiro, publicada em 1955, pela Revista de Antropologia (NOGUEIRA, op. cit.).
Suely Koffes (1996, p. 44) chama atenção para o contexto histórico não só dos EC, mas principalmente de suas críticas. Ao afirmar que "a crítica a um modelo cultural e funcional [acontece] para afirmar um modelo histórico e estrutural", Koffes constrói uma interlocução dos EC com seus críticos - nesses termos, em especial, com a crítica de Wortmann. Situar essa crítica no momento em que a análise das tradições antropológicas no país passava também pela distinção entre intelectualismo e empirismo (ibidem, p. 46), sugere que as avaliações dos EC exprimiam as demandas intelectuais e os lugares institucionais a partir dos quais eram feitas ${ }^{12}$.

Embora as considerações de Wortmann sejam de um momento bem posterior aos anos 1950, alguns dos aspectos por ele levantados já estavam colocados no debate contemporâneo aos EC. Oracy Nogueira (1955a), por exemplo, embora fosse um "partidário" dos EC, apontava também algumas das limitações desses estudos, e comentava as objeções que se Ihe faziam. Em $1953^{13}$ já destacava o problema aparentemente contraditório da realização de um estudo monográfico, mas com pretensões à formulação de análises mais generalizantes. Noutras palavras, era preciso extrair, de um estudo sobre um objeto específico, informações que pudessem servir de subsídio para uma reflexão ampliada do contexto social nacional. Nesse sentido, o primeiro ponto era o da escolha, entre as possibilidades de dados da vida social a se colher, daqueles mais relevantes para a investigação.

Consorte (op. cit., p. 72) e Durham (1982, p. 167) acrescentam que faltava aos EC uma preocupação mais explícita em não apenas mostrar a comunidade como um exemplar do que estava sendo investigado, mas demonstrar a sua relação com o contexto nacional, com as instituições da sociedade tomada sob um olhar mais amplo. Em razão dessa questão, os EC foram também considerados estudos "alienados" da sociedade. Surgiram críticas quanto à superficialidade dos EC em relação à investigação de questões mais importantes da sociedade (PRADO JÚNIOR, op. cit., p. 27-29), como o acirramento das tensões no mundo do trabalho em razão da disputa entre o capitalismo e o socialismo que avançava no bojo da Guerra Fria.

As transformações pelas quais as comunidades em estudo estavam passando eram tributárias de uma conjuntura política e econômica que conduzia o país ao sistema capitalista. Esse movimento era alvo de críticas dos marxistas ao modelo de capitalismo moderno que se impunha de maneira devastadora. Apesar dessas críticas, a inserção das comunidades interioranas no mundo capitalista estava no horizonte dos cientistas sociais envolvidos na produção de EC, como aponta Charles Wagley em seu estudo na Amazônia, ao considerar benéficas as transformações orientadas para a aproximação das comunidades rurais ao modo de vida urbano, e a articulação do trabalho de cientistas sociais nos 
programas de desenvolvimento socioeconômico (WAGLEY, 1957[1953]).

Esse é justamente um dos pontos levantados por Octávio lanni, no início dos anos 1960, em suas objeções aos EC ${ }^{14}$. Para lanni, embora a intenção de oferecer subsídios aos administradores responsáveis por programas de educação e saúde pública, por exemplo, tenha impulsionado a realização desses estudos, o alcance limitado da descrição dos dados levantados não produzia conhecimento interpretativo acerca dos fenômenos sociais, cuja inteligibilidade era essencial para a adaptação desses programas às reais condições de mudança das comunidades rurais (IANNI, 1961, p. 114-115).

Além disso, a crítica de lanni aos EC se estende às considerações sobre o papel que teriam na história das ciências sociais. Como vimos anteriormente, Nogueira (1955a) havia apontado a importância dos EC para a superação da produção sociológica considerada ensaísta. lanni mostra, por sua vez, que os EC, embora constituíssem apenas um método de investigação, foram confundidos com um "modelo teórico de compreensão da realidade [social]", prejudicando a articulação dos aspectos levantados ao arcabouço teórico que permitiria construir, a partir deles, uma análise explicativa da sociedade brasileira. E, assim, segundo o autor,
14. Vale ressaltar, como aponta Jackson (2009), que as críticas aos EC feitas por lanni e outros cientistas sociais ligados à USP pode ser compreendida também mediante a dimensão institucional do debate acadêmico. Mostrando a face política das divergências teóricas dos "uspianos" aos EC, Jackson revela que os EC foram utilizados como representantes do modelo de pesquisa que diferenciava o trabalho desenvolvido na USP do trabalho desenvolvido na ELSP.

Alguns fenômenos continuamente examinados nesses estudos etnosociológicos, tais como isolamento e contato sociocultural, desorganização, individualização, mudanças sociais e culturais, etc., são encarados geralmente da mesma perspectiva, sem que se procure ultrapassar as limitações das focalizações clássicas do assunto. Não se nota qualquer tentativa de renovar a compreensão tradicional desses processos, descobrindo-lhes as dimensões que as primeiras investigações não conseguiram formular. Ao contrário, repetem-se as reconstruções descritivas, orientadas para as manifestações globalizadoras. [grifos do autor] (ibidem, p. 117)

A crítica de lanni vai de encontro às considerações de Nogueira (op. cit.), revaloriza a produção considerada ensaísta e redimensiona o papel dos EC na história das ciências sociais no Brasil, deslocando-os da centralidade que tinham no estabelecimento de parâmetros diferentes de regime de cientificidade na produção sócio-antropológica. Werneck Vianna (1997, p. 188-189) também mostra a retomada da linha de abordagem do ensaísmo e do "ângulo largo das questões macroestruturais" no mesmo período em que as ciências sociais estão se institucionalizando e os EC passam a ser realizados. Para o autor, uma sociedade em pleno processo de mudança, como a brasileira naquele período, não só impulsionava a comunidade científica a explicar tal processo, a apontar os obstáculos na transição ao moderno e os caminhos para superá-los, como tornava 
15. Holanda (op. cit., p. 126) também critica a tentativa de utilizar, com rigor metodológico, uma técnica que foi experimentada, desenvolvida e orientada para uma determinada realidade social bastante diversa da que se havia estabelecido no Brasil. O autor se refere ao fato de que o método era estimulado por fatores localmente definidos e que, ao que parece, à nossa realidade nacional seria necessário ou um método específico, ou uma adaptação desse método, ou ainda um menor rigor quanto à sua aplicação metodológica. imprescindível a ideia de síntese.

Não obstante, a contribuição dos EC realizados no país para o desenvolvimento das ciências sociais não se resume às expectativas de compreensão da realidade social criadas a seu respeito. Apesar das limitações apontadas pelos críticos, como o caráter essencialmente descritivo, os EC representam o esforço de compreensão da sociedade brasileira a partir do levantamento de dados, considerando-os relacionados à conjuntura de transformações socioculturais especialmente da década de 1950.

Guerreiro Ramos faz uma crítica contundente aos EC no que concerne à importação de modelos de desenvolvimento e de investigação. Durante o II Congresso Latino-americano de Sociologia, realizado no Rio de Janeiro e em São Paulo, no ano de 1953, enquanto presidente da Comissão de Estruturas Nacionais e Regionais, o sociólogo desaconselhou "a transplantação literal de medidas adotadas em países plenamente desenvolvidos" e a aplicação de "recursos na prática de pesquisa sobre minudências da vida social, devendo se estimular a formulação de interpretações genéricas dos aspectos global e parciais das estruturas nacionais e regionais" (RAMOS, 1995[1957], p. 105-106) ${ }^{15}$.

Sua visão aponta a interpretação dos EC como reprodução de uma Sociologia estrangeira pouco ou nada articulada às realidades nacionais. Por isso mesmo, não seria então capaz de contribuir substancialmente nem para uma análise da sociedade brasileira, nem para conduzi-la ao desenvolvimento. Ao invés disso, contribuía para o "esclarecimento de pormenor da vida rural brasileira de secundaríssima importância", tendo papel relevante apenas no sucesso das "atividades de certa casta de especialistas em problemas rurais, sanitários, imigratórios, aculturativos, assistenciais, educacionais e administrativos" (ibidem, p. 142,147).

Florestan Fernandes (op. cit., p. 225) rebate tal crítica ao inferir que "eliminar os 'detalhes da vida social' do campo de trabalho do sociólogo equivaleria, atualmente [década de 1950], em dissociar a interpretação dos fenômenos sociais da pesquisa empírica sistemática". Ora, tal dissociação vinha de encontro ao movimento que buscava superar a produção sociológica anterior ao processo de institucionalização das ciências sociais, considerado por muitos cientistas um sinal do desenvolvimento dessas disciplinas no Brasil. Para além dessa questão, Florestan também chama atenção ao fato de que, em razão da diversidade econômica e sociocultural característica das cinco regiões brasileiras, o estudo desses "detalhes da vida social" configurariam uma alternativa segura para o conhecimento das estruturas da vida social e não impossibilitavam a elaboração de análises mais generalizantes (ibidem). 
O debate entre Guerreiro Ramos e Florestan Fernandes foi registrado por Guidi (1962): a autora articula essa discussão à ideia corrente de que era necessário haver uma mudança social nos países subdesenvolvidos ${ }^{16}$ e que as ciências sociais tinham uma contribuição importante a dar nesse processo. Na visão da autora, essa contribuição era dada também pelo conhecimento das culturas e estruturas sociais das localidades investigadas através dos EC, o que tornava os comentários de Guerreiro Ramos inapropriados dentro desse embate. Guidi chega a afirmar que "tendo em vista a grande extensão do nosso país e o número representativo de sua população, é acentuada a nossa carência de estudos de comunidade" (ibidem, p. 46-47). Lima (1999, p. 177) também critica as considerações de Guerreiro Ramos em relação aos EC, mostrando que nesses trabalhos havia mais que o exercício da pesquisa de campo: "tratava-se de uma sociologia e uma antropologia que aspiravam constituir-se em bases de pedagogia de transformação do caboclo (...), de ruptura com o multissecular processo de transmissão cultural".

O caráter de investigação articulada aos projetos de desenvolvimento e mudança social presente em diversos EC, como destacou Guidi, atesta o engajamento dos cientistas sociais na condução do país à modernidade. As críticas apresentadas sinalizam que os EC tiveram um papel relevante no acionamento do conhecimento das ciências sociais às questões nacionais, como também compuseram o debate em torno da aplicação metodológica, da adequação teórica e de outros recursos que confeririam o caráter científico à produção dessas disciplinas.

O debate em torno dos EC na década de 1950 indica que havia o interesse de investigar comunidades rurais que ainda mantinham algum grau de preservação da cultura tradicional, em franco processo de desaparecimento face ao desenvolvimento do país. Sua necessidade partia do entendimento de que era preciso intervir racionalmente nesse processo. No entanto, conforme os estudos foram sendo produzidos e o país deixava de ser agrário e rural para ser predominantemente industrial e urbano, os EC foram sendo substituídos por outros recursos de pesquisa e interpretação do social, mais afeitos à compreensão das transformações sociais que se processavam (CONSORTE, 1996, p. 66-67). Procuramos, ao revisitar esse debate, trazer os EC de volta como aspectos históricos importantes no campo das ciências sociais, mostrando sua articulação com temas importantes na década de 1950, a exemplo da mudança social e do desenvolvimento.

\section{Considerações Finais}

O objetivo do nosso trabalho foi mapear as posições assumidas por cientistas
16. A articulação da mudança social com a ideia de subdesenvolvimento indica que a promoção do desenvolvimento era uma preocupação que ultrapassava os interesses nacionais. Como mostra Esco$\operatorname{bar}(1996$, p. 13-14), as ideias em torno dos países subdesenvolvidos, do Terceiro Mundo, foram formuladas num cenário internacional em que os países centrais julgavam benéficas ações que pudessem transformar economicamente, socialmente e culturalmente o restante do planeta. As ações de instituições internacionais, como ONU e UNES$\mathrm{CO}$, destinadas a países subdesenvolvidos como o Brasil, atestam que essa era uma preocupação mundial. Logo, a contribuição que os cientistas sociais tinham a dar aos projetos de mudança social seria ampla. Guidi afirma que os EC seriam "a maior contribuição que a Antropologia Social tem prestado aos programas de cooperação [entendida nesse período como assistência técnica, sanitária, educacional, etc.] interdisciplinária para a resolução de problemas mundiais de desenvolvimento e, como tal, oferecem interesse a especialistas de outras disciplinas" (GUIDI, op. cit., p. 47). 
sociais acerca dos EC, no intuito de contextualizá-los intelectualmente. Balizando essa discussão, que compreendeu sua conceituação e características, as temáticas abordadas e seu papel na história das ciências sociais, levantamos algumas questões que constituíram o debate sobre esses estudos, de forma a contemplar considerações tanto de autores que avaliaram positivamente os EC, como daqueles que levantaram objeções à sua realização. Destacamos não só as críticas que foram realizadas no momento em que diversos EC estavam sendo produzidos no país, incluindo os balanços que se fizeram nas décadas posteriores.

A partir desse mapeamento, verificamos que, no âmbito intelectual, o conhecimento do modo de vida das populações rurais produzido pelos EC ofereceu aos cientistas sociais dados empíricos que se coadunavam com a perspectiva de trabalho científico característica do processo de institucionalização das ciências sociais no Brasil. Os EC contribuíram sobremaneira para que a realidade social dessas comunidades fosse conhecida, permanecendo os dados sociais e ecológicos contidos nesses estudos como fonte profícua para que pesquisadores possam produzir análises explicativas.

Esses dados constituíram material utilizado na compreensão da dinâmica social brasileira entre as décadas de 1940 e 1960, especialmente, mas também evidenciaram questões metodológicas e cognitivas que perpassaram a produção intelectual sobre o país no período. Por isso mesmo, apontamos os EC como uma marca importante na história das ciências sociais no Brasil, visto que estão ligados ao surgimento de instituições acadêmicas no campo das ciências sociais, constituíram meio de treinamento de diversos cientistas e relevante elo entre seus trabalhos e amplos projetos de pesquisa social em sintonia com a temática do desenvolvimento.

Dessa forma, procuramos resgatar alguns aspectos da produção de EC no Brasil, mostrando que os mesmos contribuíram significativamente para as interpretações dos cientistas sociais acerca da sociedade brasileira e estiveram comprometidos com uma perspectiva de mudança social. Contrapomo-nos, assim, à visão que prevaleceu na bibliografia a respeito desses estudos, que os concebe como investigações meramente descritivas, alheias às grandes transformações econômicas, políticas e sociais que se processavam no Brasil na década de 1950. Alinhamo-nos à perspectiva que, analisando contribuições e limitações dos EC, recoloca-os no debate acadêmico, repensando o seu papel na história das ciências sociais.

Abstract: The purpose of this article is to examine the literature about Community Studies 
(CS) in Brazil, highlighting their intellectual context of production and the debates evoked by them, especially between the 1940's and 1960's. As a research method arising from Anthropology on communities in social change process, CS was used in United States between 1920's and 1950's, and played a fundamental role in the institutionalization of Social Sciences in Brazil. Three aspects are highlighted on CS production: first, in a conceptual approach, we discuss their definitions, origins and relation to main topics in the 1950's. The second aspect is related to the role of CS in the history of Social Sciences, especially their institutionalization process. By the end, we revisit the debates between social scientists about the sociological work standard to be developed at that time.

Keywords: Community Studies, Social Sciences History, Social Change, Institutionalization of Social Sciences, Development.

\section{Referências Bibliográficas}

ARENSBERG, Conrad M.; KIMBALL, Sólon T. "O método do estudo de comunidade." In: F. Fernandes (org.). Comunidade e Sociedade. São Paulo: Cia. Editora Nacional / Edusp, 1973.

BOMENY, Helena. Darcy Ribeiro: sociologia de um indisciplinado. Belo Horizonte Ed. UFMG, 2001.

BOTELHO, André. "Ciência pelo desenvolvimento: a escrita pública de José Leite Lopes". In: A. Botelho et al. O Moderno em questão: a década de 1950 no Brasil. Rio de Janeiro: Topbooks Editora, 2008.

. "Passado e futuro das interpretações do país". Tempo Social, Re-

vista de sociologia da USP, vol. 22, n. 1., 2010.

CAVALCANTI, Maria Laura V. de C. "O aspecto humano de nossos dados" In: M. C. Maio; G. Villas Boas (orgs.) A relação Pierson/Nogueira, a etnografia e a abordagem das relações raciais. Ideais de modernidade e sociologia no Brasil - ensaios sobre Luiz Aguiar Costa Pinto. Porto Alegre, Editora da Universidade/ UFRGS, 1999.

CONSORTE, Josildeth Gomes. "A educação nos estudos de comunidade no Brasil". Educação e Ciências Sociais, vol. 1, n² 2, Rio de Janeiro, CBPE, 1956.

. "Os estudos de comunidade no Brasil: uma viagem no tempo". In: M. I. L. Faleiros; R. A. Crespo (orgs.). Humanismo e Compromisso: ensaios sobre Octávio lanni. São Paulo: Editora da Universidade Estadual Paulista, 1996. 
CORRÊA, Mariza. Histórias da Antropologia no Brasil: 1930-1960, testemunhos: Donald Pierson e Emilio Willems. São Paulo: Vértice, Editora Revista dos Tribunais; (Campinas, SP), Editora da Universidade Estadual de Campinas, 1987.

COSTA PINTO, Luiz de Aguiar. O Negro no Rio de Janeiro - relações de raça numa sociedade em mudança. 2a ed. Rio de Janeiro, Ed. UFRJ, (1998[1953]). . Sociologia e Desenvolvimento. Civilização Brasileira, (1970[1963]).

CRUZ, Levy. Papel e uso da hipótese nos "Estudos de Comunidade". Anais do II Congresso Latino-americano de Sociologia. Rio de Janeiro, 1953.

DURHAM, Eunice R. "Os problemas atuais da pesquisa antropológica no Brasil”. Revista de Antropologia, vol. 25, São Paulo, 1982.

FERNANDES, Florestan. “Arthur Ramos 1903-1949. Os problemas da 'Antropologia Brasileira'”. Revista do Museu Paulista, Nova Série, vol. IV, 1950.

. A Etnologia e a Sociologia no Brasil. São Paulo: Ed. Anhambi, 1958. . Mudanças Sociais no Brasil. Aspectos do desenvolvimento da sociedade brasileira. 3a Ed. São Paulo: Difel, 1979.

GOLDWASSER, Maria Júlia. "Estudos de Comunidade: teoria ou método?" Revista de Ciências Sociais, vol. 5, n. 1, Fortaleza, UFCE, 1974.

GUIDI, Maria Laís M. “Elementos de análise dos ‘Estudos de Comunidades' realizados no Brasil e publicados de 1948 a 1960". Educação e Ciências Sociais, vol. 10, n. 19, jan, 1962.

HERMANN, Lucila. Evolução da estrutura social de Guaratinguetá num período de trezentos anos. São Paulo: IPE-USP, 1948.

HOLANDA, Sérgio Buarque de. Tentativas de Mitologia. São Paulo, Ed. Perspectiva. ("Tradição e Transição I, II e III". Diário de Notícias, Rio de Janeiro, 10, 17 e 24 de outubro de 1948), 1979.

IANNI, Octávio. "O método em 'Uma comunidade amazônica'". Sociologia, vol. 20, n. 4, 1958.

. "Estudo de comunidade e conhecimento científico". Revista de Antropologia, vol. 9, n. 1-2, 1961.

JACKSON, Luiz Carlos. "Tensões e disputas na sociologia paulista (1940-1970)". Revista Brasileira de Ciências Sociais, vol. 22, n. 65, out, 2007. 
. "Divergências teóricas, divergências políticas: a crítica da USP aos

'estudos de comunidades'”. Cadernos de Campo, São Paulo, n. 18, 2009.

KOFFES, Suely. "As pedras e o arco: os estudos de comunidade e a atualidade de antigas questões." In: M. I. L. Faleiros; R. A. Crespo (orgs.) Humanismo e Compromisso: ensaios sobre Octávio lanni. São Paulo: Editora da Universidade Estadual Paulista,1996.

LIMA, Nísia Trindade. Utopia sociológica substitui utopia higienista. Reflexão sobre o Brasil e seus contrastes no período de institucionalização universitária das Ciências Sociais (1933-1964). Um Brasil chamado sertão. Rio de Janeiro: Revan, 1999.

LIMONGI, Fernando. “A Escola Livre de Sociologia e Política em São Paulo". In: S. Miceli. História das Ciências Sociais no Brasil. São Paulo: Vértice, 1989.

LYND, Robert S.; LYND, Helen M. Middletown - a study in contemporary american culture. Orlando: Harcourt Brace \& Co, (1957[1929]).

MAIO, Marcos Chor. "O Projeto Unesco e a agenda das ciências sociais no Brasil dos anos 40 e 50". Revista Brasileira de Ciências Sociais, vol. 14, n. 41, 1999.

. "O Racismo no Microscópio: Oracy Nogueira e o Projeto UNESCO".

In: Estudios Interdisciplinarios de America Latina y el Caribe. Vol. 19, n 1 , jan/ jun, 2008.

MAIO, Marcos Chor; LIMA, Nisia Trindade. "Tradutores, intérpretes ou promotores de mudança? Cientistas sociais, educação sanitária rural e resistências culturais (1940-1960)". Sociedade e Estado, Brasília, v. 24, n. 2, maio/agosto, 2009.

MASSI, Fernanda. "Franceses e Norte-americanos nas Ciências Sociais Brasileiras (1930-1960)". In: S. Miceli. História das Ciências Sociais no Brasil. São Paulo: Vértice, 1989.

McCOMB, Marlin R. ; FOSTER, George. "Kalervo Oberg, 1901-1973 (Obituary)". American Anthropologist, New Series, vol. 76, n. 2, jun, 1979.

MELATTI, Julio Cezar. "A Antropologia no Brasil: um roteiro. Boletim Informativo e Bibliográfico de Ciências Sociais (BIB)”, n. 17, Rio de Janeiro, ANPOCS, 1984.

MICELI, Sérgio. História das Ciências Sociais no Brasil. São Paulo: Vértice, 1989.

MOREIRA, Maria Sylvia Franco. "O estudo sociológico de comunidades". Revista de Antropologia, vol. 11, n. 1-2, 1963. 
MUSSOLINI, Gioconda. "Emílio Willems: Cunha - Tradição e Transição em uma Cultura Rural do Brasil" [Resenha]. Revista do Museu Paulista. Nova Série, Vol. III, 1949.

NOGUEIRA, Oracy. "Os Estudos de Comunidades no Brasil”. Revista de Antropologia, vol.3, n. 2, 1955a.

. "Relações Raciais no Município de Itapetininga". In: R. Bastide, F. Fernandes (orgs.), Relações Raciais entre Negros e Brancos em São Paulo. São Paulo, 1955b.

OBERG, Kalervo. "Interesses da comunidade e programas de desenvolvimento rural". Anais do Seminário Nacional sobre as Ciências Sociais e o Desenvolvimento de Comunidade Rural no Brasil. Rio de Janeiro: Ed. SSR, 1961.

OGBURN, William F. "Cultural Lag as Theory (1957)". On culture and social change. Edited by Otis Dudley Duncan. Chicago: Phoenix Books; University of Chicago Press, 1964.

OLIVEIRA, Lucia Lippi. A Sociologia do Guerreiro. Rio de Janeiro: Ed. UFRJ, 1995.

OLIVEIRA, Nemuel da Silva. Estudos de Comunidade, Ciências Sociais e Saúde: o ciclo de pesquisas no Vale do São Francisco na década de 1950. Dissertação (Mestrado em História das Ciências e da Saúde). Casa de Oswaldo Cruz/Fiocruz, Rio de Janeiro, 2010.

PEIXOTO, Fernanda; SIMÕES, Júlio A. "A Revista de Antropologia e as ciências sociais em São Paulo: notas sobre uma cena e alguns debates". Revista de Antropologia, v. 46, n² 2, São Paulo, USP, 2003.

PIERSON, Donald. "Robert E. Park: sociólogo pesquisador". Sociologia, vol. 6, n. 4, 1944.

. Cruz das Almas. Rio de Janeiro: Livraria José Olympio Editora,

1966.

. O Homem no Vale do São Francisco. 3 Tomos. Ministério do Interior, SUVALE, Rio de Janeiro, 1972.

PRADO JÚNIOR, Caio. "Métodos Sociológicos". Fundamentos. Ns 7-8, Dez. 1948 / Jan, 1949.

RAMOS, Alberto Guerreiro. Introdução Crítica à Sociologia Brasileira. Rio de Janeiro: Ed. UFRJ, (1995[1957]). 
RAMOS, Arthur. "Os grandes problemas da antropologia brasileira". Sociologia, vol. X, n. 4, 1948.

REDFIELD, Robert. Civilização e Cultura de Folk: estudo de variações culturais em Yucatan. São Paulo: Livraria Martins Fontes Ed., 1949.

SORJ, Bila. "Demarcando o campo da sociologia: a contribuição de Costa Pinto" In: M. C. Maio, G. Villas Boas (orgs.) Ideais de Modernidade e Sociologia no Brasil - ensaios sobre Luiz de Aguiar Costa Pinto. Porto Alegre: Ed. Universidade/ UFRGS, 1999.

VALLADARES, Lícia do Prado. "A visita do Robert Park ao Brasil o "homem marginal" e a Bahia como laboratório". Caderno $C R H$, vol. 23, n. 58, Salvador, jan./ abr. , 2010.

VIANNA, Luiz Werneck. A revolução passiva: iberismo e americanismo no Brasil. Rio de Janeiro: Renavan, 1997.

VILA NOVA, Sebastião. "O singular e o universal nos estudos de comunidade" In: M. I. Faleiros, R. A. Crespo (orgs.) Humanismo e Compromisso: ensaios sobre Octávio Ianni. São Paulo: Editora da Universidade Estadual Paulista, 1996.

VILLAS BÔAS, Gláucia. "De Berlim a Brusque, de São Paulo a Nashville - a sociologia de Emilio Willems entre fronteiras". Tempo Social, Rev. Soc. da Usp, vol. 12, n. 2, nov, 2000.

. Mudança Provocada: passado e futuro no pensamento sociológico brasileiro. Rio de Janeiro: Editora FGV, 2006.

. A Vocação das Ciências Sociais no Brasil: um estudo da sua produção em livros do acervo da Biblioteca Nacional, 1945-1966. Rio de Janeiro: Fundação Biblioteca Nacional, 2007.

WAGLEY, Charles. Amazon Town - a study of man in tropics (1953). Ed. em português: Uma comunidade Amazônica, São Paulo, Nacional, 1957.

WAGLEY, Charles; AZEVEDO, Thales de. "Sobre métodos de campo no estudo de comunidade". Revista do Museu Paulista, Nova Série, vol. V., 1951.

WALLACH, Jennifer J. "New Introduction". Deep South: a social anthropological study of caste and class. Columbia: The University of South Carolina Press, (2009[1941]).

WILCOX, Clifford. Robert Redfield and the development of American Anthropology. United Kingdom, Lexington Books, 2004. 
WILLEMS, Emilio. "A solução do problema rural brasileiro como mudança social provocada". Sociologia, n. 5, vol. 2, 1943.

. O problema rural brasileiro do ponto de vista antropológico. São Paulo: Secretaria da Agricultura, Indústria e Comércio do Estado de São Paulo, 1944.

. Tradição e transição em uma cultura rural do Brasil, São Paulo:

Difusão Europeia do Livro, 1947.

WORTMANN, Klaas. "A Antropologia brasileira e os estudos de comunidade". Universitas, n. 11, 1972. 